\title{
GRAZIANO GASPARINI
}

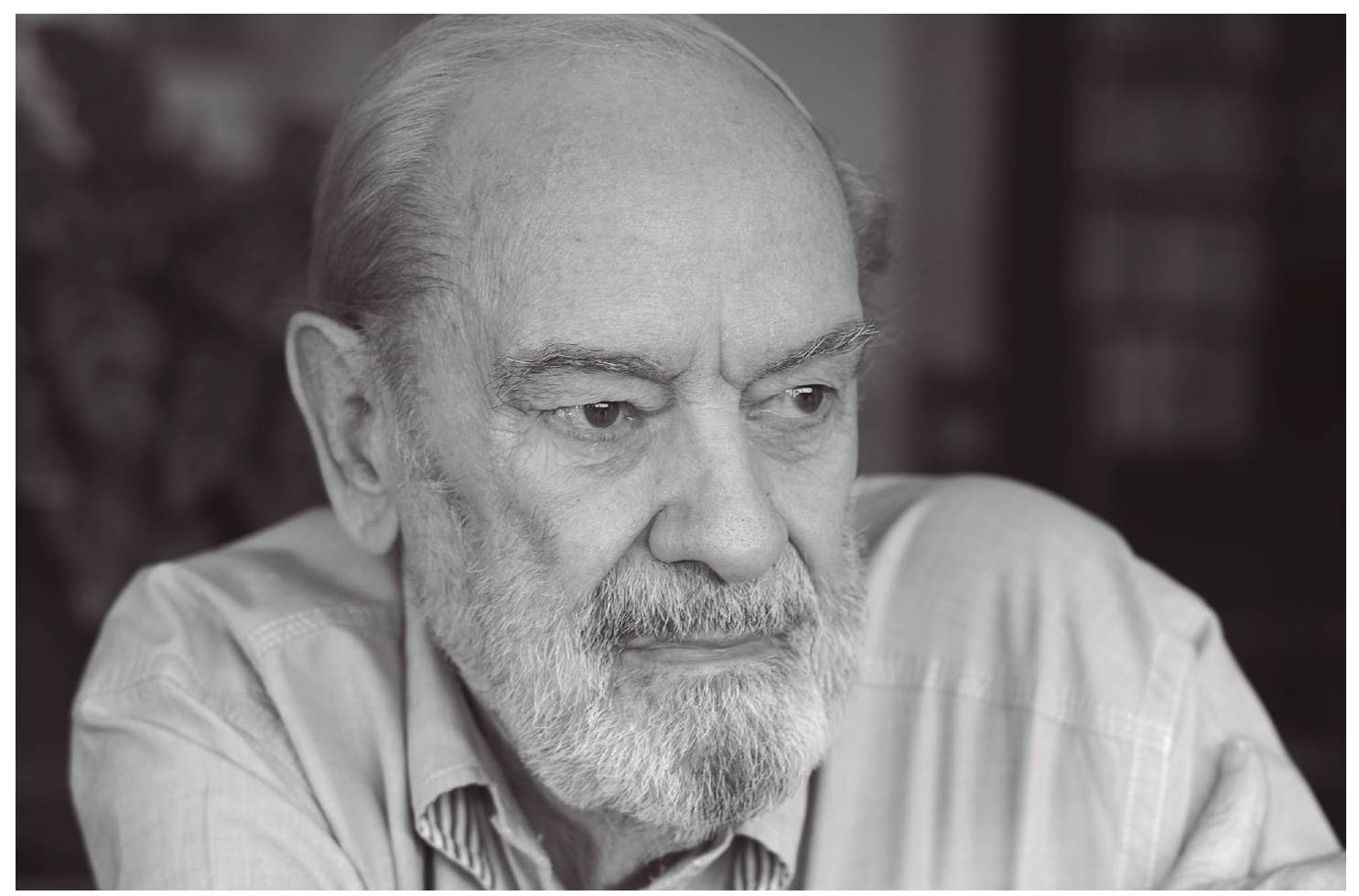

Figura 1. Graziano Gasparini (1924-2019). En Archivo fotográfico personal de Paolo Gasparini, extraído de la Revista Quiroga № 8, 2015.

A fines del año 2019 dejó de existir en Caracas, a los 95 años de edad, el arquitecto Graziano Gasparini, destacado y controversial investigador de la historia de la arquitectura americana, profesor universitario e incansable defensor del patrimonio cultural, no solo de Venezuela, su patria adoptiva, sino de toda América. Nacido en el norte de Italia en 1924, hizo sus estudios universitarios en la Facultad de Arquitectura de la Universidad de Venecia, graduándose como Arquitecto en 1948, a los 24 años de edad.

Antes de concluir su carrera, Gasparini trabajó con Carlo Scarpa, renombrado arquitecto y notable figura de la restauración de monumentos en Italia. Scarpa era su profesor en la Facultad de Arquitectura y como promotor de la prestigiosa Bienal de Arquitectura de Venecia, le confió al joven Gasparini la misión de promover la participación de Brasil, Perú y Venezuela en ese importante evento. El mismo año de su graduación universitaria lo envió a visitar las capitales de los tres países, en un corto viaje de dos semanas. Estando Gasparini en Caracas, se produjo un golpe militar que derrocó al gobierno y ocasionó, debido al rechazo internacional, el aislamiento de Venezuela durante varios meses. Por esta situación, no pudo cumplir el itinerario propuesto antes de su regreso a Italia.

Como él mismo narra en una entrevista', su permanencia en Venezuela se prolongó por cuatro meses y gracias a que había demanda de profesionales arquitectos, empezó a trabajar para una empresa constructora. Durante esos meses, viajó al interior del país para conocer sus poblados históricos y monumentos. Luego volvió a Italia, pero con la convicción de que su futuro estaba en este país sudamericano y al mes siguiente retornó para afincarse definitivamente. Una década después empezó su carrera docente en la Facultad de Arquitectura y Urbanismo de la Universidad Central de Venezuela, enseñando en el área de Historia de la

1. Graziano Gasparini Arquitecto, Historiador y Restaurador. Revista Quiroga No. 8, julio- diciembre 2015. Caracas, Venezuela. 
devenir Vol. 7, N¹3, ENERO - JUNIO 2020, PP. 5-8 - IN MEMORIAM | ISSN 2312-7562 | E-ISSN 2616-4949

UNIVERSIDAD NACIONAL DE INGENIERÍA, LIMA

doi: https://doi.org/10.21754/devenir.v7i13.924

Arquitectura. Era reconocida su erudición en el tema y su conocimiento de los monumentos venezolanos que había registrados en diapositivas. Se valoraban los viajes de estudio que organizaba para que sus alumnos conocieran su patrimonio histórico.

Una de las iniciativas más destacadas que tuvo a lo largo de su carrera universitaria fue la creación del Centro de Investigaciones Históricas y Estéticas, adscrito a la Facultad de Arquitectura y Urbanismo, que él mismo dirigió durante 17 años. El Centro de Investigaciones, con sus 33 años de existencia, publicó una revista especializada en temas relacionados con la historia de la arquitectura y el patrimonio cultural, Boletín del Centro de Investigaciones Hístoricas y Estéticas.

Fue considerada la mejor publicación de su género en América, gracias a las vinculaciones de su Director que publicaba artículos de los más renombrados investigadores y académicos, aunque no concordarán con su línea de pensamiento en la interpretación de la arquitectura americana.

Desde su juventud tuvo especial interés por las diversas corrientes en la interpretación de la arquitectura andina. A través del Centro de Investigación que dirigía y su revista especializada, estableció vínculos con investigadores del arte y la arquitectura con los cuales fue consolidando sus propios postulados. Asumió una actitud crítica en contra de la exaltación del período colonial y se mostró contrario a la añoranza del tiempo pasado que mostraban algunos estudiosos del tema. Sostenía que el período colonial se caracterizó por la avidez desenfrenada por acumular riquezas y que para ello impuso condiciones infrahumanas a los trabajadores indígenas obligados a pagar tributos y al trabajo obligatorio de la mita. En su razonamiento, la arquitectura del período colonial era producto directo de esas condiciones sociales que otorgaban bienestar para unos pocos y miseria para muchos, lo que hacía inexistente un clima apacible de bienestar.

Por esa razón se declaraba contrario a que muchos historiadores sublimaran aquel período y decía que estaban influidos por un malentendido nacionalismo que restaba validez a sus interpretaciones. Argumentaba que la arquitectura colonial era diferente a la que se edificó en España, porque las condiciones no fueron las mismas y por ello debía considerarse su carácter provincial; que la arquitectura colonial era representativa de la clase dominante, un grupo reducido y privilegiado por las barreras de casta y raza; y que una mayoría subyugada y avasallada era obligada a materializar esa obra.

Impugnaba la denominación de arquitectura mestiza porque, según él, los artesanos indígenas, al interpretar de manera personal e imperfecta los modelos trasmitidos desde Europa, produjeron en lugares periféricos una obra ausente de formas estéticas. La pericia rudimentaria de esos artesanos hizo un arte popular provincial para la casta dominante. Además, cuestionaba la referida denominación, derivada de una categoría racial, por confundir un tema estilístico del campo del arte y de la arquitectura con un fenómeno étnico.

La postura de Gasparini tuvo eco en publicaciones, ponencias y simposios sobre historia del arte y la arquitectura, de connotados historiadores como Erwin Walter Palm, Antonio Bonet Correa, George Kubler y otros que en la prolongada polémica sobre el origen y significado del barroco andino, se conocieron en los medios especializados como los "hispanistas".

Por el otro lado, se ubicaban los "indigenistas" que habían teorizado por primera vez acerca del estilo mestizo como Angel Guido (1896-1960), Emilio Harth-Terré (1899 - 1983); y en años más recientes Teresa Gisbert, José de Mesa, Leopoldo Castedo, Damián Ballón, Ramón Gutiérrez y otros investigadores. Como bien señala el erudito estudio de Gauvin Bailey, publicado en español el 2018², ninguno de los estudiosos del grupo calificado como "hispanistas" había nacido en Latinoamérica, mientras los "indigenistas" sí eran originarios de América del Sur.

En este recuento de las ideas y del pensamiento de Graziano Gasparini que nos permite atisbar aspectos de su intenso quehacer intelectual, cabe recordar la polémica epistolar que tuvo con el arquitecto Emilio Harth-Terré en 1961. Por esa fecha, Gasparini, que tenía 37 años, había argumentado apasionadamente en contra del estilo mestizo en el Congreso Internacional de Historia del Arte en Nueva York, y propuso separar el barroco andino de cualquier idea de contribución indígena. Por su parte, Harth-Terré, uno de los estudiosos que teorizaron sobre el estilo mestizo y recordado por sus proyectos arquitectónicos en estilo Neo Colonial, le dirigió una carta a

2. Bayley, Gauvin Alexander, El Barroco Andino Hibrido, ediciones El Lector, s.r.l., Arequipa, 2018 
Gasparini — que se conserva en la Biblioteca de la Universidad de Harvard — en la que le responde con argumentos razonables, pero refiriéndose a Kubler, el maestro de Gasparini. Sostenía Harth-Terré que el sajón en general y en particular el puritano no entienden el mestizaje, porque en sus colonizaciones dejaron de lado al nativo y, por eso mismo, se sigue designándolo peyorativamente. Como es de suponer esa respuesta exarcebó el debate y dividió aún más a los investigadores.

Cabe añadir que quienes no concordaban con los postulados anteriores consideraban que si hubo una integración de la cultura indígena que se dejó sentir en las artes del periodo colonial y que sus manifestaciones, en muchos casos, provenían de sus ancestros precolombinos que se reservaron y mimetizaron durante los dos primeros siglos de colonización, para aflorar y exteriorizarse en el siglo XVIII. No estaban de acuerdo en que la arquitectura mestiza haya sido una forma provincial del arte culto, porque se expresa en imágenes plásticas de origen manierista europeo, divulgadas en grabados y viñetas de libros, que circulaban en los estratos más ilustrados. Son los mismos modelos eruditos que en manos de los canteros indígenas, adquieren su propia interpretación.

Coherente con sus conceptos, en 1972 presentó su libro: América, Barroco y Arquitectura de 586 páginas, ilustrado con fotografías y dibujos, obra en la que reitera su inconformidad con la historiografía de la arquitectura americana, insistiendo en que la limitada interpretación de los modelos y un oficio imperfecto de los artesanos indígenas, produjo expresiones de imitación, que no son creativas. Su faceta de investigador y fructuoso escritor se puso en evidencia desde su arribo a Venezuela en 1948, con artículos sobre los sitios históricos y ejemplos de la arquitectura del país. Una década después publicó su libro Templos Coloniales de Venezuela que constituyó una revelación debido a que no se había difundido la existencia de ese patrimonio arquitectónico religioso.

Posteriormente publicó otros libros sobre las haciendas, las fortificaciones coloniales y otros temas como los referidos a la arquitectura de los incas, de los mayas y la arquitectura popular. Cuando cumplió 91 años presentó su último libro titulado El Pasado Presente con el cual totalizó 62 obras escritas en el transcurso de su existencia.

De su producción literaria especializada, destacamos Arquitectura Inca, libro presentado en 1977 y escrito en asociación con la antropóloga norteamericana Luise Margolies. Fue considerado en los medios académicos como una notable contribución al conocimiento de la arquitectura y la etnohistoria del Tawantinsuyo.

Gasparini, fue un intelectual perspicaz y apasionado no sólo por los temas de la arquitectura sino también por la preservación del Patrimonio cultural y la restauración de monumentos, disciplina especializada en la que también fue pionero en Venezuela. En la entrevista a la que nos referimos al inicio del presente obituario, cuando le preguntaron: ¿Qué es lo que más le satisface en su vida personal y profesional?, respondió: "El haberme dedicado por placer a lo que estoy haciendo". En el campo de la restauración de monumentos sus conocimientos fueron reconocidos por el gobierno de Venezuela al designarlo como su representante en el Segundo Congreso Internacional de Arquitectos y Técnicos en Monumentos, celebrado en Venecia en 1964, oportunidad en la que suscribió la denominada Carta Internacional de la Restauración de Monumentos y Sitios, más conocida como la Carta de Venecia.

Su actividad como especialista en Conservación del Patrimonio cultural se extendió a otros países. Pasó un año en California, impartiendo conocimientos en el Getty Center. Fue además docente temporal en la Universidad de Gainsville en Estados Unidos y la Universidad Nacional Autónoma de México. EntrDCe los años de 1975 a 1980 se impartieron en Cusco, cursos semestrales de Restauración de Monumentos Arquitectónicos con el auspicio de la UNESCO, en el marco del convenio entre el Instituto Nacional de Cultura y ese organismo internacional, para la puesta en valor de monumentos del eje Cusco - Puno comprendidos dentro del Plan COPESCO. Esa formación especializada estuvo dirigida a jóvenes profesionales, becarios de América Latina y contó —además de los especialistas que laboraban en el Proyecto PER 51/539 Perú-UNESCO— con expertos a nivel internacional. En todos esos años, Gasparini participo en la enseñanza con estadías de varias semanas en Cusco, lo cual me permitió establecer vínculos de amistad con él.

Por su trayectoria, fue nombrado Director de Patrimonio del Consejo Nacional de Cultura de Venezuela e impulsó una Ley para la protección de los monumentos del país. En los años de bonanza económica de ese país, Gasparini promovió un amplio y notable plan de restauración de templos coloniales y edificacio- 
nes civiles representativas de ese período. También gracias a su trayectoria, fue designado Consultor de la UNESCO y se encargó de varias misiones relacionadas con la conservación del patrimonio edificado en países de Sudamérica.

En los inicios de los años setenta del siglo pasado, su pasión por la preservación de los bienes culturales lo llevó a escribir una severa crítica en VISIÓN, revista de circulación internacional. En ese artículo, Gasparini denunciaba ante la comunidad internacional la equivocada intervención de reconstrucción del sector de Kalasasaya del importante conjunto arqueológico del Tiwanaku en Bolivia. Esa inadmisible reconstrucción que alteró la autenticidad del monumento pre-hispánico, estuvo a cargo del Instituto Nacional de Arqueología de Bolivia, cuyo Director trató de justificar lo ejecutado, manifestando que se trataba de una campaña de ciertos intereses mezquinos que pretendían minimizar la magnitud de los antiguos vestigios.

En 1970, para el Simposio Internacional sobre Arqueología y Patrimonio Cultural organizado por el Instituto Nacional de Cultura en Paracas, concurrieron como ponentes tanto Gasparini como el referido Director de Arqueología de Bolivia. Sorpresivamente, el funcionario boliviano distribuyó entre los participantes un opúsculo agraviante contra Gasparini y luego se retiró sin exponer ni sustentar la controvertida intervención en Tiwanaku. Como era de esperar, los asistentes se solidarizaron con el agraviado y la artimaña no surtió efecto.

Sin duda, Graziano Gasparini era una persona polémica y apasionada que no se amilanaba cuando se trataba de defender ideas o impedir acciones contrarias al patrimonio cultural; pero, al mismo tiempo, fue un intelectual con un gran desempeño, muy humano y solidario, que legó a las nuevas generaciones de arquitectos su extensa obra escrita y sus aportes al conocimiento de las disciplinas que cultivó con tanta perseverancia.

Roberto Samanez Argumedo 